\title{
Ergonomic recommendations when texting on mobile phones
}

\author{
Ewa Gustafsson* \\ Occupational and Environmental Medicine, University of Gothenburg, Box 414, SE-405 30 Göteborg, Sweden.
}

\begin{abstract}
The aim of this report was to give ergonomic recommendations in order to prevent musculoskeletal symptoms/disorders among young people due to intensive texting on mobile phones. In a study of 56 Swedish young adults (19-25 years, 41 with musculoskeletal symptoms in neck and/or upper extremities and 15 without symptoms) registration of thumb movements with electrogoniometry, muscle activity with electromyography and observation of texting technique were conducted during texting on mobile phones. The results showed differences in physical load between the group with musculoskeletal symptoms and the group without symptoms. There were also found differences in muscle activity and kinematics between different texting techniques. These differences could not be explained by the asymptomatic group having symptoms but may be a possible contribution to their symptoms. According to these results it can be recommended to support the forearms, to use both thumbs, to avoid sitting with the head bent forward and to avoid texting with high velocity in order to prevent musculoskeletal disorders when using mobile phones for texting.
\end{abstract}

Keywords: Working technique, Thumb movements, Posture, Cell phone

\section{Introduction}

There has been a dramatically increased use of mobile phones for texting especially among young people all over the world during the last years. In Sweden $100 \%$ of those aged 15-24 years have access to a mobile phone and $93 \%$ of them are texting an average day [1]. In $200975 \%$ of those aged 12-17 years in the USA have their own mobile phone and $88 \%$ of those are text-messagers. Half of them are texting 50 or more messages per day and one-third over 100 messages per day [2].

Despite this widespread use of mobile phones for texting especially among young people and reports of musculoskeletal disorders from the hand and forearm due to intensive texting on mobile phones [3, 4, 5] there are still only a few studies published on risk factors for musculoskeletal disorders due to this specific and increasing use of mobile phones.
The aim of this report was to give ergonomic recommendations to prevent musculoskeletal symptoms/disorders among young people due to intensive texting on mobile phones.

\section{Material}

Fifty-six young adults (19-25 years, 41 with musculoskeletal symptoms in neck and/or upper extremities and 15 without symptoms) were recruited from a Swedish cohort of young adult ICT users [6]. The young adults performed texting tasks on a mobile phone while registration of thumb movements, muscle activity and observation of texting technique were conducted.

A biaxial electrogoniometer (Model SG 110; Biometrics, Gwent, UK) was used to register thumb adduction/abduction and flexion/extension. The muscle

\footnotetext{
* Corresponding author. E-mail: ewa.gustafsson@amm.gu.se Tel.: +46 3178662 81; fax: +46 31409728
} 
activity was registered with surface EMG (Muscle Tester ME 3000P8, Mega Electronics Ltd, Kuopio, Finland) in six muscles: the right extensor digitorum, the right first dorsal interossei, the right abductor pollicis longus, the right abductor pollicis brevis and the pars descendent of the right and left trapezius muscle.

\section{Possible risk factors for musculoskeletal disorders when texting on mobile phones}

The results in the study showed differences in physical load between the group with musculoskeletal symptoms and the group without symptoms. There were also differences in muscle activity and kinematics between different texting techniques. Furthermore these differences could not be explained by the asymptomatic group having symptoms but may be a possible contribution to their symptoms.

It was found to be more common in the group with symptoms to sit with the head bent forward, to sit without forearm support and to enter text with one thumb rather than two compared to the group without symptoms. It was also found that use of forearm support decreased the muscle activity in the trapezius muscles and that high velocity in the thumb movements was associated with higher muscle activity in the extensor muscles in the forearm compared with low/moderate velocity $[7,8]$.

\section{Ergonomic recommendations when texting}

According to the above results following recommendations can be given in order to prevent muscu- loskeletal disorders when using mobile phones for texting.

- Support the forearms (e.g. against an armrest, the thighs or a table)

- Use both thumbs

- Do not sit with the head bent forward

- Do not text with high velocity

\section{References}

[1] Nordicom. (2010). The Swedish Media Barometer 2009: Nordic Information Centre for Media and Communication Research, University of Gothenburg.

[2] Lenhart, A., Ling, R., Campbell, S., Purcell, K., 2010. Teens and Mobile Phones. $M$ communication studies, http://pewinternet.org/ /media//Files/Reports/2010/PIPTeens-and-Mobile-2010-with-topline.pdf.

[3] Menz, R.J., 2005. 'Texting' tendinitis. Medical Journal of Australia, 182 (6), 308.

[4] Ming, Z., Pietikainen, S., and Hanninen, O., 2006. Excessive texting in pathophysiology of first carpometacarpal joint arthritis. Pathophysiology, 13 (4), 269-270.

[5] Gordon, S., 2008. Beware the "Blackberry Thumb". The Washington Post http://www.washingtonpost.com/wpdyn/content/article/2008/06/15/AR2008061500481.html.

[6] Thomée, S., Eklöf, M., Gustafsson, E., Nilsson, R., and Hagberg, M., 2007. Prevalence of perceived stress, symptoms of depression and sleep disturbances in relation to information and communication technology (ICT) use among young adults - an explorative prospective study. Computers in Human Behavior 23, 1300-1321.

[7] Gustafsson, E., Johnson, P.W., and Hagberg, M., 2010. Thumb postures and physical loads during mobile phone use a comparison of young adults with and without musculoskeletal symptoms. Journal of Electromyography and Kinesiology, 20, 127-135.

[8] Gustafsson, E., Johnson, P.W., Lindegård, A. and Hagberg, M., 2011. Technique, muscle activity and kinematic differences in young adults texting on mobile phones. Ergonomics, Vol.54,No.5,May2011,477-487. 